\title{
Trust in the Market: Institutions versus Social Capital
}

\author{
Caterina Galluccio \\ Department of Law and Social Science, Universitàdegli Studi Gabriele d'Annunzio di Chieti Pescara, Italy \\ Email: caterina.galluccio@unich.it
}

How to cite this paper: Galluccio, C. (2018). Trust in the Market: Institutions versus Social Capital. Open Journal of Political Science, 8, 95-107.

https://doi.org/10.4236/ojps.2018.82008

Received: January 22, 2018

Accepted: April 5, 2018

Published: April 8, 2018

Copyright $\odot 2018$ by author and Scientific Research Publishing Inc. This work is licensed under the Creative Commons Attribution International License (CC BY 4.0).

http://creativecommons.org/licenses/by/4.0/

\begin{abstract}
The principal objective of this research paper is to gain an in-depth understating on what is the critical driver of trust in the market, whether it is social capital or institutions. Works by several authors such as Robert Putnam, Ostrom, Francis Fukuyama, Douglass North, among others were used as primary sources for the research. It is, however, essential to note that there are no proven theories on what is the primary driver of trust in the market, but it is imperative to study a market to know whether institutions or social capital are the primary driver of trust in that particular market. The merits, demerits, and the composition of trust in social capital and institutions are identified in this paper. Generalized trust, values, and norms of reciprocity and cooperation are viewed as the key pillars of social capital and have an undeniable influence on confidence in markets. Trust in institutions, on the other hand, is influenced by the type of institution and institutional change. Organizations are viewed more formally by players in a market and are conceived to be credible; hence one cannot ignore their influence on trust in the market. According to this paper, trust in markets is driven by both social capital and institutions. One cannot solely rely on one and ignore the other. The interdependent relationship existing between institutions and social capital has a significant impact on economic, financial and financing decisions of the players in a market. Developing an even-handed, balanced employment of trust in social capital and trust in institutions could positively influence the socio-economic conditions of any market. In other words, to achieve their primary objective, which is profit maximization, the participants in a market have to learn how to strike a balance in the levels of trust they place on either social capital or institutions.
\end{abstract}

\section{Keywords}

Trust, Social Capital, Institutions 


\section{Introduction}

Trust and confidence in the market legitimize decisive and efficient actions from the consumers and create the conditions that favor organizations. A solid foundation of trust is necessary for sufficient retention and expansion of market forces. Policies have to be strategically developed and tailor-made to meet the level of confidence the market has on an organization. Economic development cannot grow without trust in the trading market. Investors from all over the world are likely to place their investment capital in markets they have confidence in.

Trust is core in investigating how certain markets are driven as it incorporates the ability of teams to immediately resolve common challenges, ability to coordinate the distribution of resources regarding public goods or making and implementing policies, which members of a network must comply with, commonly referred to as norms (Paxton 1999: p. 100).

The source of confidence remains undefined accentuating the fact that there are no existing theories that have made any connection between confidence, social capital, and institutions (Portes 1998: p. 16). Yet, there are few studies that focus on microeconomic links between the measurement of trustworthiness and the results including variables such as economic development that indicate that the magnitude of trust differs depending on the economic, institutional environments and social aspects. Ostrom (2000) also indicates that civil customs convictions have a close correlation with growth and institutions despite the fact that there are several ways in which organizations might influence feedback to trust (p. 197).

However, there arises a question on whether trust in the market is driven by institutions or by social capital (Qurniati, Febryano, \& Zulfiani, 2017: p. 1204). The discussion in this paper will try to answer the question and make a conclusion based on the findings.

\section{Trust as Driven by Social Capital}

Social capital can be best explained as a model of the commercial stock where individuals connect to each other to conduct trading amongst themselves which is marked with trust, market actors and associations who create products and services for their common goal (Bourdieu, 1980: p. 2). It is a beneficial economic thinking that denotes the relations among different persons and bodies which could be considered to be mutually beneficial and valuable economically in the near and far future. These systems and networks of trust can prove to be a substantial and robust asset for one to have in their possession. This term is also associated with different definitions such as a resource and its value both tangible and intangible. It can also be used to bring out the relationship among these resources as well as to define the effect of mutual friendship on the properties encompassed (Adler, 2001: p. 230).

Social capital's origin can be backtracked to the year 1926 with focus on ar- 
guments by Lyda J. Hanifan. She stipulated that social capital was not only a tool for raising individuals' living standards but also a structure that could generally elevate a person's level of social welfare. During this time in history, social capital was regarded to as a tool for macroscopic units like the nation and the society inclusive (Fukuyama, 2001: p. 14).

Putnam in his thesis on 'Making Democracy Work,' illustrates social capital as comprising of three fundamental pillars. These were: ethical responsibilities and norms, social principles, that discussed the notion of trust in a community or society, and communal networks, with emphasis on voluntary association (Putnam, Leonardi, \& Nanetti, 1994: p. 53; Ferragina, 2013: p. 48). In the thesis, Putnam describes a proper functioning economic environment that is integrated with a high-level politics as a result of successful accumulation of social capital. Adam Seligman also notes that a modern society on a consensus is built on a network of trust within citizens, their families, institutions or the general organizations, religious denominations, civic associations, among others. A legitimate modern society as well is founded on the citizens' dependability on the authority of the government.

Putnam's arguments can be viewed as a continuation of the present day American theory of pluralism (Putnam, 2001: p. 45). Further on, Putnam made a classification of social capital by laying it out in two distinct forms, bridging and bonding social capital (Nahapiet \& Ghoshal, 1998: p. 245). Bridging social capital arises as a result of linkages among people with different backgrounds who build networks to share their ideas, thoughts, or useful economic and social information. It, however, lays emphasis on the magnitude as opposed to the value of relationships. Bonding, on the other hand, is a network of individuals with similar social background who share the same characteristic(s) such as being employees of a similar organization or company, with more focus on quality rather than the quantity of the relationship (Edwards \& Foley, 1998: p. 130).

Adler and Kwon did similar classifications of social capital with the bridging group having a focus on social resources within the network, which helps in the realization and explanation of success for firms and organizations within their competitive rivalry. Social norms define what kind of actions by individuals or groups are considered proper or correct, improper or incorrect. Norms have their potential consequences, either a reward or punishment which is determined by the effects, costs, and advantages that an individual takes into account when exercising choice. There is no legal or formal basis for social norms, and at times, it conflicts with the law.

\subsection{Drivers of Trust}

Trust can be noted as an individual actor doing something for the general good within an aim that his/her action will be rewarded and not from their knowledge of the other person in the interaction network. Some may also define trust as a suspension of judgment. However, the goal is to create a positive development of 
mutual relation. In the present world, there a is need to believe that when we leave our comfort zones, based on familiarity, we make an attempt to enter a zone dominated by contingency, complexity, and risk (Kinghorn, 2013: p. 5). Trust is needed most when the role expectations and intimate relationships are no longer helpful. This means that people have to rely on one another to achieve optimal functionality as individuals and as a society.

Trust is crucial in individual's daily life due to the effects it carries in a relationship with people and the community as a whole. Trust building process involves constant communication and interaction with each other. These interactions help people to organize themselves in a position that they benefit and avoid any harm from the relationship (Øyen, 2002: p. 3). Some of the sources of trust for individuals include religion, tribe and family relationships. Refusal to be open to receiving help from others by trusting them to do so would mean losing opportunities that could change one's life and add value to it, both economically and socially.

According to Breuskin, (2012) generalized trust, co-operation, and generalized reciprocity form the basis of social capital (p. 35). Trust in general is considered as the heart of social capital since it is an irreplaceable part of any democratic culture. Confidence acts as an indicator of the potential readiness of citizens to cooperate with one another in their involvement in civic endeavors and extends further beyond the boundaries of personal interaction to incorporate people who are strangers to each other. The attitude towards this generalized trust should be distinguished from the one among people well known to each other as it goes beyond kinship and friendship (Nooteboom, 2006: p. 43).

There are several reasons why generalized trust is necessary; these may include the fact that it reduces doubts and uncertainty of future unseen events hence enabling continuous opportunistic behavior among individuals in the network. According to Fafchamps (2006), generalized trust helps in raising the desire in people to take risks regarding the productive exchange (p. 1186). It helps in the reduction of bureaucratic structures by enabling smooth and harmonious functioning of organizations and interactions. This trust has a close correlation to economic development and growth, and this is due to its impact on the scales of a firm, society, and government policy-making process (Evans 1996: p. 1125).

Individual prejudice, behaviors, and tendencies are key influencers in the formation of trust. Some people find it hard to put their faith in others especially if they do not know them on a personal level, while others believe 'too easily.' In any network, such variations in character are bound to exist and either slow down or accelerate the process of building social capital. Individuals who are too hesitant impede the process as they may miss out on valuable opportunities while those that are considered to be fast actors will build their social capital within a short span of time (Knack \& Keefer, 1997: p. 1255).

According to Hardin (2002), trust matters as it makes one susceptible to the 
deeds of other people and opens one up to the possible occurrence of loss (p. 83). This means that one has faith in a particular outcome without placing much consideration on the variables that could negatively affect the expected outcome. Generalized trust, therefore, is a vital aspect of social capital since all players have an inter-dependent relationship for a common benefit. They rely on each other to gain reliable and trustworthy ideas and information that they use either for business purposes or any other ones. More so, linkages in which participants maintain mutual trust in each other form robust and valuable social and economic networking ties that could prove to be extremely useful for the long haul.

\subsection{Co-Operation and Generalized Reciprocity}

Putnam in his thesis also mentions that any society predecessors of which have passed down a considerable amount of social capital, in a manner of cultures, mutuality, and systems of civil commitment fosters voluntary cooperation with much ease by enabling synchronized action, therefore, improving the efficiency of the said society (1984: p. 89). When using social capital, there are no guarantees or security to assure the involved (Coleman, 1988: p. 100). Therefore, it is important for the individuls to be cooperative and live up to the set expectations and agreements to ensure that a harmonious working relationship is upheld. Social capital is also driven by collective action, (Hardin, 2015: p. 125) and lack of cooperation among the individuals involved becomes a significant obstacle in the functioning of the network ultimately leading to its collapse.

Sobel (2002) in his research, states that generalized reciprocity means that individuals perform certain acts with an expectation that they will get something else in return (p. 140) People act in a trustworthy manner mostly because they assume or are aware they will acquire something out of it in exchange. Putnam accentuates the benefits of mutual interchange and why it enhances cooperation. These include:

1) It leads to the increase in the cost of absconding. This effectively means that the one who chooses to defect from his/her obligations could be removed from the network and would stand to lose a lot.

2) It nurtures and promotes high customs and standards relating to reciprocity. Participants also provide information to their networks as a strategy that if they may need to use their social capital, it may be available to them as they had there before accorded help to a member(s) of the network.

3) It enables secure information flow and communication. Whenever there is the reciprocity concept, these come naturally as none of the participants want to be left out lest they not reap the benefits of this social capital.

4) It exemplifies the successes of the past as a result of cooperation and stipulates an outline for collaborations in the future. This means that it shows how previous partnership led to success and also provides a clear and detailed plan to be followed by the people involved, which demonstrate how they can collaborate 
to ensure continuity of such trends of success.

\subsection{Social Capital as a Driver of Trust in Markets}

Social capital is a significant stimulus on trust in markets. In today's world, a majority of information and opportunities present in the local and global scene are made available to those who are connected to the channels of information or networks. Digitalization of the modern world has promoted the growth of social capital. A research conducted by Kinghorn (2013) shows that globalization and social media have provided a platform for many to form networks with people all around the globe and get access to privileged information through such social capital. Digital platforms such as online communities like Facebook, Twitter, Whatsapp, and search engines like Google, Wikipedia among others have made networking and information gaining easy by speeding up communication and opening up people to resources that they would otherwise had no access to.

Social capital also facilitates informal contract enforcement (Myeong \& Seo, 2016: p. 322). For instance, an individual would agree to give information to another person as long as the other will also give him information if he ever needs it. This kind of trust without question on reliability or credibility in social capital, therefore, cannot be taken lightly as an influence of markets. In other scenarios, social capital in a market is illustrated in a small scale business where a shopkeeper allows customers he trusts to take goods on credit without asking for security, having faith that they will certainly make their arrears in due time. On a much larger scale, business owners who have an existing relationship can carry out transactions that require large amounts of money (capital intensive) on credit using social capital which smoothens the running of the business in cases where there is an inadequate or limited supply of physical or money capital. Those that do not have access to social capital may, therefore, suffer a great deal as a result of this (Uzzi, 1999: p. 502).

Humans are social beings in nature and trust and assurance are inevitable concepts in conducting business. Mutual trust and cooperation among the players in the market are important considerations in use of social capital. Therefore, one cannot deny that social capital is a primary driver of trust in many markets due to the personal touch and appeal it offers (Rothstein \& Stolle, 2001: p. 78).

\section{Trust as Driven by Institutions}

Institutions refer to human-made norms that structure the political-economic as well as the social interactions within the society; this comprises of both the formal and informal rules. Historically these institutions are known to have been created with the sole purpose of maintaining order and help in the reduction of unseen certainty in interactions. Economically, the combination of institutions and the standard constraints within economics results to the definition of choice set hence they influence the transaction and production cost which impact profitability of economic activity (Nahapiet \& Ghoshal, 1998: p. 251). 
Institutions grow and develop quickly, linking the former with the current and the forthcoming. They offer incentive organization of the economy. As the economic arrangements evolve, they influence the course of economic modification in regards to progress, unproductivity or regression. For social capital to thrive, it should be connected to an official, political and lawful institution. It cannot operate independently but depends on the government or politics to survive (Uzzi, 1999: p. 490). State rules and legislative bodies have a direct influence on the quantity of social capital. People's ability to start cooperative relations and institute social trust is highly determined by the governing bodies and the policies implemented.

Institutions can be built to promote the value transformation of the people to aid and balance new democracies. They also help to bring a solution among teams struggling with the issue of a shared pool of resources. An individual will gain trust and confidence in an institution if well satisfied by the activities and policies of that organization. If the foundation establishes weak and harsh dogmas, it will push away its customers. Edwards and Foley (1998) argue that people tend to be feel appreciated where their views are taken positively and their complaints are acted upon (p. 129).

According to the General Social Surveys (GSS), assurance in institutions has a greater impact on personal confidence than does the social capital. The state as a basis of social capital formation is crucial to the formation of public capacity. However, it's the citizens to establish whether they trust the government or not for it to ascertain its ability to gain confidence in them. For instance, the government can inaugurate contracts that relay details and observe lawmaking and implement freedoms and regulations that punish the criminals, defend the minorities and devotedly uphold the incorporation and contribution of its citizens.

According to Ostrom (2000), people, after maximizing their wealth, will always keep interacting with other players if the play is recurrent, when they get adequate details on the other competitor's previous performance, and when the number of participants is minimal (p. 197). However, when the competition is upside down, institutions find it hard to put up with the game if it's not repetitive, information about the other partner is missing, and when the players are many (Weber, 2002: p. 16). Numerous cooperatives allow little expense on transaction and production under the earlier circumstances. These institutions need to solve the issue of social support to achieve the set goals and objectives. Resources are required to define and impose exchange treaties. If all people had a similar goal (maximization of profit), dealing would involve considerable assets. In case of personal maximization of wealth tendency and uneven data on the viable characteristics of what is traded and transitioned, expenses are the essential element of economic progress. Associations and their determination in ensuring that the set laws are adhered to, influence the charge of transacting (Adler, 2001: p. 229).

Rothstein and Stolle (2002) in their research note that established institutions 
promote the merits of cooperative resolutions or the fee of defection, to practice the theoretical terms used in the game (p. 52). In cases of the terms of transaction and production cost, institutions lower the price so that the expected profits can be achieved. Political and economic bodies play a fundamental role in an efficient institutional atmosphere (Kinghorn, 2013: p. 5). Facilities are essential in problem-solving of companies set up in a competitive environment. Market exchange, contracts or vertical incorporation are viewed as relevant answers to the challenges facing businesspeople under different aggressive conditions.

To elaborate on the issue of confidence in institutions, we apply the 'encapsulated interest' description of faith (Uzzi, 1999: p. 490). Here, trust is centered on credibility or more precisely, on perceived reliability, in a relationship involving three parties, say, A, B, and C. For example, A believes B on issues concerning C. Since A has faith in B's intention to acting in a trustworthy manner concerning point $\mathrm{C}, \mathrm{A}$ believes in $\mathrm{B}$ to the point that B's concern encapsulates the desires of $\mathrm{A}$, on issues C. Hardin explains that as long as there is a trust relationship, personal relations among individuals on matters concerning various topics, the parties will always be trustworthy.

In scenarios whereby, A trust people of type B in all circumstances, a complete trust called the 'Putnam account' is applied. In this case, the burden of explaining the relevant causal methods is very extensive. It will require several accounts of a vibrant procedure where the public actors spread the belief that they have with other people in their relations to a common trust with people whom they had never had any experience.

The existence of corporations in a general social environment can highly influence the trustworthiness of the participants in the particular circumstances in a way that an established relationship among the players is formed. It is evident that institutions have a crucial effect on the trust of the consumers and stabilization of an economy. Hardin (2002: p. 191) maintains that agencies work against opportunities which may be very harmful to entrepreneurs. They also eradicate leading causes of insecurity and enhance a healthy relationship between the traders on different issues.

Studies prove that organizations may have a ripple effect on the trust among various operators in any economic setup (Heller, 1998: p. 35). For this to happen, institutions provide the players with incentives to act in a trustworthy or untrustworthy manner. Corporations should also positively influence collective trust on belief or denial of players through availing details concerning the anticipated character of others. If the institutions motivate and encourage actions, they will nurture fidelity (Evans, 1996: p. 1111). For example: if one is conscious of the frauds in a particular trade or operation, and the estimated charge of punishment outnumber the anticipated gains of fraud, his ideal plan will be to stay honest or faithful. Therefore, he may be termed as faithful in matters concerning this particular transaction, so other people who are aware of this regulation, and adhere to it, may have a valid reason to trust him. This aspect of faith will lead to 
the establishment of long-lasting relationships if no party deviates from the agreed terms. No person would desire to conduct dealings with a liar due to uncertainty in character. If one's character warrants questioning, it will be sporadic to do business with other entrepreneurs who are aware of his or her flaws. These vices, in turn, repel customers, suppliers, investors, financiers, or any other parties that would desire to conduct business with such an individual (Uzzi, 1999: p. 489).

\subsection{Types of Institutions}

Research conducted by Lam, Zhang, and Ong (2005: p. 473) shows that a majority of institutions, formal or informal, try their level best to come up with incentives and sanctions that attract other business partners. In doing so, they establish a great trust relation. In most cases, it's tough for the institutions to control the risk of fraud in the economy, and in cases in which they manage to, the trust may not be a suitable method to analyze the economy. Trust is a descriptive term and is most appropriate in social cooperation where there is a danger of one party dodging the contract (Six, Van Zimmeren, Popa, \& Frison, 2015: p. 24). If organizations can be explained in matters of obedience to the established institution's laws, there would be no essence of using trust as a portion of the explanation. Invoking the function of an organization is what is required. Conviction and constancy is important explanatory aspect when social institutions to be clarified cannot be lessened to poor institutional adherence.

Due to the above factors, another mechanism for organizational effect on trust is developed. That is, the dissemination of details pertaining day-to-day activities. Institutions initiate accepted beliefs concerning the character of others. With the knowledge of institutional laws, the participants in the market can determine a constant expectation about how other players will behave in corporate social conditions. If the law commands that standard character, social actors have an opportunity to access the information to bring up expectations concerning the probability that other players will participate and eventually resolve to conduct themselves diligently (Heller, 1998: p. 35). By doing so, the institutions simply take a broad view on market expectation. Besides, the reality brought about by the effects of institutions on market beliefs stipulate that the participants can start cooperating and trusting one another in different ways that cannot be abated by the straight outcomes of organization-induced anticipations. To realize this, we have to put in mind ways, in which corporations might aid the dynamic procedure of gaining knowledge about the faithfulness of other members (Gregory, 1999: p. 65).

Hardin (2002: p. 125) argues that compliance with the rules implemented by the institutions affects one's belief in the possibility of others to maintain the same level of cooperation and trustworthiness. This process will encompass three core stages. Initially, actor A surveys actor B's conformity with the usual rules amended in the corporation to manage situation C. Secondly, from this 
data, actor A obtains the deduction that player B can be trusted, and that the agent will cooperate in yet to come situations of $\mathrm{C}$. Thirdly, A will be more willing to deal with $\mathrm{B}$ in instances of $\mathrm{C}$ whether or not the institutional regulations control the state. It can be a result of A developing total trust on actor B.

\subsection{Institutions Change}

Change in institutions profoundly affects the market on issues regarding trust and influences the flow of information among the actors (North, 1990: p. 33). The efficiency of institutions in the maintenance of trust in the market is also likely to reduce. Knight argues that natural bodies, instead of leaning on competence in the overall sense, influence conflicts between actors on matters to do with powers (Farrell \& Knight, 2003: p. 561). He also stipulates the settings in which an authority-centered bargaining theory can enlighten organizational development and change, and the surroundings in which other methods can deliver better results. The negotiation tactic insists on distributional profits for particular participants, while the contract and evolutionary approaches emphasize developed market efficiency (Gabre-Madhin, 2001: p. 24). The evolutionary method depends on the concept of salience and performs best when the members agree on the gains brought about by the equilibrium in the market. Contract approach, on the other hand, is likely to present an honest explanation when the participants possess the same level of authority. That is, none is more compelling than the other.

In a research done by Burawoy (1976), he notes that in cases where there is a breakdown of the governing institution, some participants will be more affected than the others (p. 55). They will be forced to coordinate with those that are less affected to ensure progress in their transactions. In contrast, powerful actors will try to look for means to profit themselves and gain control of the market. They may elevate or lower prices as they please regardless of the impact their actions will have on the other traders (Heller, 1998: p. 35). These acts affect the levels of trust among the actors since traders with less power will feel oppressed by those that wield power and therefore disengage them. In situations where all the players face the same challenges, they form collaborations to ensure that they overcome their challenges as a team. However, if they decide to face challenges independently, they are likely bound to fail.

Institutions have significant control over trust issues since they avail information on the probable activities of others to other actors in different settings (Farrell \& Knight, 2003: p. 556). For example, if a person realizes that an organization is strict on its dealings and disciplines untrustworthy character, they may be forced to act in a faithful and trustworthy manner, and others who operate in the organization will believe the individual on matters concerning the issue. Consequently, an organization may stipulate the required behavior in the institution which will give me more information on the trustworthiness of all members.

Gilson (2003: p. 1460) in his research found that in every market setup, oper- 
ators come from different regions and have varying cultural beliefs and in order to foster a harmonious and successful relationship among these parties, certain rules and regulations should be implemented. Government institutions play a fundamental role in the implementation of laws that ensure market actors are secure, competition is healthy, customers are protected and there exists proper infrastructure. Putting in place such lucrative incentives boosts the morale of those working in such set-ups.

Unhealthy competitive actions like destroying or stealing the competitor's property lead to disagreements. It is near impossible for the afflicted to ever trust the oppressor (Tendler \& Amorim, 1996: p. 407). Such acts should be avoided and instead teamwork among the players should be encourage to enable them to realize their goals and objectives. In cases where there are no institutions to govern the market, traders should be organized. Institutions should also put laws that favor rather than oppress the market actors in place. The rules and regulations should be simple and easy to understand, flexible, and should cater for the rights of the citizens (Heller, 1998: p. 35).

\section{Conclusion}

Trust in the market is an integral part of the success of an economy. It enables the members to conduct their dealings amicably thus leading to the realization of profits and the general growth and development of the economy. Where there is no trust among the market actors, many entities will fail. Such a consequence is resulting from many engaging in fraudulent activities to gain an added advantage over their competitors.

Social capital is crucial in establishing trust among participants and ensuring unity among members. It also creates a platform where members can share ideas that lead to the accomplishment of the set goals. This trend in return leads to creativity and innovation of the entities. On the other hand, institutions come up with the policies that should be followed by every participant in the market. If the rule stipulates that no member is allowed to operate in a certain market, the law has the final say. Institutions profoundly determine how actors in the market relate and trust each compared to the social capital. Every activity carried in networks of social capital must be at par with the law. Anything besides what is stated in the constitutional law will lead to illegality and hence punishment from the government.

For there to be trust in the market, both the social capital and the institutions should be well integrated since the two are interdependent. The actors in the market should also observe proper business ethics to ensure that they do not engage in activities that may harm the other parties. The networks that build social capital should also be held accountable for the nature of the information they avail. In conclusion, this research work shows that trust in the market is earned and not guaranteed; it is not dependent on one driver but is built on the foundations of dependency and reliability on both social capital and institutions. 


\section{References}

Adler, P. S. (2001). Market, Hierarchy, and Trust: The Knowledge Economy and the Future of Capitalism. Organization Science, 12, 215-234.

https://doi.org/10.1287/orsc.12.2.215.10117

Bourdieu, P. (1980). Le capital social. Actes de la recherche en sciences sociales, 31, 2-3.

Breuskin, I. (2012). Social Capital and Governmental Institutions. Living Reviews in Democracy, 3, 35.

Burawoy, M. (1976). Beyond Contract: Work, Power and Trust Relations. Alan Fox, 55.

Coleman, J. S. (1988). Social Capital in the Creation of Human Capital. American Journal of Sociology, 94, 95-120. https://doi.org/10.1086/228943

Edwards, B., \& Foley, M. W. (1998). Civil Society and Social Capital beyond Putnam. American Behavioral Scientist, 42, 124-139.

https://doi.org/10.1177/0002764298042001010

Evans, P. (1996). Government Action, Social Capital and Development: Reviewing the Evidence on Synergy. World Development, 24, 1119-1132. https://doi.org/10.1016/0305-750X(96)00021-6

Fafchamps, M. (2006). Development and Social Capital. The Journal of Development Studies, 42, 1180-1198. https://doi.org/10.1080/00220380600884126

Farrell, H., \& Knight, J. (2003). Trust, Institutions, and Institutional Change: Industrial Districts and the Social Capital Hypothesis. Politics \& Society, 31, 537-566. https://doi.org/10.1177/0032329203256954

Ferragina, E. (2013). The Socio-Economic Determinants of Social Capital and the Mediating Effect of History: Making Democracy Work Revisited. International Journal of Comparative Sociology, 54, 48-73. https://doi.org/10.1177/0020715213481788

Fukuyama, F. (2001). Social Capital, Civil Society and Development. Third World Quarterly, 22, 7-20. https://doi.org/10.1080/713701144

Gabre-Madhin, E. Z. (2001). Market Institutions, Transaction Costs, and Social Capital in the Ethiopian Grain Market (Vol. 124, p. 24). Washington DC: International Food Policy Research Institute.

Gilson, L. (2003). Trust and the Development of Health Care as a Social Institution. Social Science \& Medicine, 56, 1453-1468.

Gregory, R. J. (1999). Social Capital Theory and Administrative Reform: Maintaining Ethical Probity in Public Service. Public Administration Review, 59, 63-75.

https://doi.org/10.2307/977480

Hardin, R. (2002). Trust and Trustworthiness (pp. 28-193). New York, NY: Russell Sage Foundation.

Hardin, R. (2015). Collective Action (p. 125). Abingdon-on-Thames: Routledge.

Heller, F. A. (1998). Organizational Participation: Myth and Reality (p. 35). Oxford: Oxford University Press.

Kinghorn, J. (2013). The Internet: An Investigation into the Contemporary Sources of Social Capital. Sigma: Journal of Political and International Studies, 30, 5.

Knack, S., \& Keefer, P. (1997). Does Social Capital Have an Economic Payoff? A Cross-Country Investigation. The Quarterly Journal of Economics, 112, 1251-1288. https://doi.org/10.1162/003355300555475

Lam, Y. H., Zhang, Z., \& Ong, K. L. (2005). Trading in Open Marketplace using Trust and Risk. In IEEE/WIC/ACM International Conference on Intelligent Agent Technol- 
ogy (pp. 471-474). Piscataway, NJ: Institute of Electrical and Electronics Engineers.

Myeong, S., \& Seo, H. (2016). Which Type of Social Capital Matters for Building Trust in Government? Looking for a New Type of Social Capital in the Governance Era. Sustainability, 8, 322. https://doi.org/10.3390/su8040322

Nahapiet, J., \& Ghoshal, S. (1998). Social Capital, Intellectual Capital, and the Organizational Advantage. Academy of Management Review, 23, 242-266.

Nooteboom, B. (2006). Social Capital, Institutions and Trust (p. 43).

North, D. C. (1990). Institutions, Institutional Change and Economic Performance (p. 33). Cambridge: Cambridge University Press.

Ostrom, E. (2000). Social Capital: A Fad or a Fundamental Concept. Social Capital: A Multifaceted Perspective, 172, 195-198.

Øyen, E. (2002). Social Capital Formation: A Poverty Reducing Strategy (p. 3).

Paxton, P. (1999). Is Social Capital Declining in the United States? A Multiple Indicator Assessment. American Journal of Sociology, 105, 88-127. https://doi.org/10.1086/210268

Portes, A. (1998). Social Capital: Its Origins and Applications in Modern Sociology. Annual Review of Sociology, 24, 1-24. https://doi.org/10.1146/annurev.soc.24.1.1

Putnam, R. (2001). Social Capital: Measurement and Consequences. Canadian Journal of Policy Research, 2, 41-51.

Putnam, R. D., Leonardi, R., \& Nanetti, R. Y. (1994). Making Democracy Work: Civic Traditions in Modern Italy (p. 53). Princeton, NJ: Princeton University Press.

Qurniati, R., Febryano, I. G., \& Zulfiani, D. (2017). How Trust Influence Social Capital to Support Collective Action in Agroforestry Development? Biodiversitas, 18, 1201-1206.

Rothstein, B., \& Stolle, D. (2001). Social Capital and Street-Level Bureaucracy: An Institutional Theory of Generalized Trust. In ESF Conference Social Capital: Interdisciplinary Perspectives (pp. 71-83). United Kingdom: Exeter.

Rothstein, B., \& Stolle, D. (2002). How Political Institutions Create and Destroy Social Capital: An Institutional Theory of Generalized Trust. In Delivery at the Annual Meeting of the American Political Science Association (pp. 52-79). Boston, MA.

Six, B., Van Zimmeren, E., Popa, F., \& Frison, C. (2015). Trust and Social Capital in the Design and Evolution of Institutions for Collective Action. International Journal of the Commons, 9, 151-176. https://doi.org/10.18352/ijc.435

Sobel, J. (2002). Can We Trust Social Capital? Journal of Economic Literature, 40, 139-154.

Tendler, J., \& Amorim, M. A. (1996). Small Firms and Their Helpers: Lessons on Demand. World Development, 24, 407-426. https://doi.org/10.1016/0305-750X(95)00155-6

Uzzi, B. (1999). Embeddedness in the Making of Financial Capital: How Social Relations and Networks Benefit Firms Seeking Financing. American Sociological Review, 64, 481-505. https://doi.org/10.2307/2657252

Weber, M. (2002). The Protestant Ethic and the "Spirit" of Capitalism and Other Writings (p. 16). London: Penguin. 